\title{
Numerical Simulation of the Sintering Process
}

\author{
Jong-in Park, Byung-kook Cho, Eun-ho Jeong \\ Technical Research Laboratories, POSCO \\ 6261, Donghaean-ro, Nam-gu, Pohang-si, Gyeongbuk, Korea \\ jip518@posco.com, cho55555@posco.com, liiil@posco.com
}

\section{Extended Abstract}

Sintering is a thermal process of converting loose fine particles into a solid coherent mass by heat without fully melting. Sintered ore manufactured from a sintering plant is used as a raw material of the blast furnace. The sintering process discharges harmful gases, such as $\mathrm{SO}_{x}$, dioxin and $\mathrm{CO}_{2}$ because of the use of coal. Therefore, sintering process has been improved continuously in order to solve the disadvantages of sintering process. In particular, waste gas recirculation system can reduce the total amount of waste gas and energy.

In this study, mathematical model that predicts the sintering process was developed. This model calculates the flow rate distribution, temperature and composition of waste gas and sinter bed profile in basic sintering process. Also, waste gas recirculation model is applied in addition.

Pot test was performed in order to improve the accuracy of the model. The pot has a window to observe fine line and it is possible to change the composition and temperature of the injection gas in order to simulate the gas recirculation process.

This model will be used as a potential tool for the basic design of sintering process including waste gas recirculation system. 